\title{
Nuevos vientos soplan en el malecón de La Habana: Reformas económicas y cambio político en Cuba
}

\section{New Winds Blowing on Havana's Malecón: Economic Reforms and Political Change in Cuba}

\section{Novos ventos sopram no Malecón de Havana: reformas econômicas e mudanças políticas em Cuba}

Jhany Marcelo Macedo Rizo

Diplomático de carrera

Embajada de Colombia en Turquía

Recibido: 18/04/2018 Aceptado: 30/06/2018

Resumen

En este ensayo se analiza la caída del socialismo real, además de diversos problemas internos y el bloqueo económico, que llevaron a Cuba al denominado Período Especial durante los años 90, frente al cual el gobierno cubano emprendió una serie de reformas económicas dirigidas a combatir sus terribles efectos y a darle un impulso a su economía nacional, fundamentada esta en la planificación pero con muy limitados resultados en términos macroeconómicos y de calidad de vida del ciudadano cubano. Debido

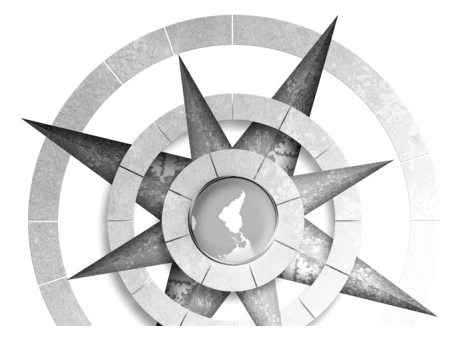

DOI: https://doi.org/10.15359/tdna.34-64.4 al carácter de algunas de esas reformas, se busca determinar si constituyen una antesala para el tránsito hacia la economía de mercado, o si, por el contrario, persiguen que el Estado siga teniendo un papel preponderante en el modelo de desarrollo pero permitiendo algunas iniciativas privadas. Aunque esta nueva apertura trae aparejada una ampliación de derechos civiles y políticos, se defiende que Cuba apunta a construir un modelo propio, tendiente a reforzar el sistema político actual y en el que en todo caso las reformas se implementen con gradualidad. Para lograr tal objetivo, el texto parte de un enfoque comparativo para revisar algunas cifras relevantes de la economía cubana y de reseñar las reformas más importantes en la última década. 
Palabras clave: Cuba, Período Especial, Reformas económicas, Embargo, Sistema político, Derechos civiles.

\section{Abstract}

The fall of real socialism, in addition to various internal problems and the economic embargo, led Cuba to the socalled Special Period during the 1990s. The Cuban government undertook a series of economic reforms aimed at combating its terrible effects and giving a boost to its planned national economy, but with very limited results in macroeconomic terms and in the quality of life of Cuban citizens. Due to the nature of some of these reforms, this article seeks to determine whether they constitute a prelude to the transition to a market economy or whether, on the contrary, they seek to have the State continue to play a preponderant role in the development model, while allowing some private initiatives. Although this new opening brings with it an expansion of civil and political rights, it is defended that Cuba aims to build its own model, tending to reinforce the current political system, in which in any case the reforms will be implemented gradually. In order to achieve this objective, the text starts with a comparative approach to review some relevant figures of the $\mathrm{Cu}$ ban economy and to overview the most important reforms in the last decade.

Keywords: Cuba, Special Period, Economic Reforms, Economic Embargo, Political System, Civil Rights.

\section{Resumo}

A queda do socialismo real, além de vários problemas internos e o embargo econômico, levaram Cuba ao chamado Período Especial durante a década de 1990. O governo cubano empreendeu uma série de reformas econômicas destinadas a combater seus terríveis efeitos e impulsionar sua planejada economia nacional, mas com resultados muito limitados em termos macroeconômicos e na qualidade de vida dos cidadãos cubanos. Devido à natureza de algumas destas reformas, este artigo procura determinar se elas constituem um prelúdio para a transição para uma economia de mercado ou se, pelo contrário, elas procuram que o Estado continue a desempenhar um papel preponderante no modelo de desenvolvimento. , embora permitindo algumas iniciativas privadas. Embora essa nova abertura traga consigo uma ampliação dos direitos civis e políticos, defende-se que Cuba pretende construir seu próprio modelo, tendendo a reforçar o atual sistema político, no qual, em todo caso, as reformas serão implementadas gradualmente. Para alcançar este objetivo, o texto começa com uma abordagem comparativa para revisar algumas figuras relevantes da economia cubana e para analisar as reformas mais importantes da última década.

Palavras chave: Cuba, Período Especial, Reformas Econômicas, Embargo Econômico, Sistema Político, Direitos Civis.

44 Nuevos vientos soplan en el malecón de La Habana: Reformas económicas y cambio político en Cuba Jhany Marcelo Macedo Rizo

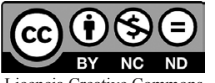




\section{Introducción}

La caída del Muro de Berlín y el consecuente derrumbamiento del bloque soviético tuvieron fuertes repercusiones en la economía cubana de principios de los años 1990, debido, en primer lugar, a la poca diversificación de su oferta exportadora, que se concentraba en algunos reducidos productos, la mayoría de los cuales tenían como destino los países del socialismo real, y en segundo lugar, a que la cooperación que la antigua URSS gestionaba hacia la isla fue segada de manera abrupta. Además, diversas causas internas, como los reducidos programas de inversiones y los indicadores negativos en sectores como el agrícola, el industrial, la producción nacional y el consumo interno, tornaron aún más difícil la situación económica cubana. Estas nuevas circunstancias, unidas al bloqueo ejercido por los Estados Unidos desde 1961, llevaron a Cuba a una crisis económica sin precedentes, que condujo a su gobierno a decretar un "Período Especial", el cual implicaba una drástica reducción en la provisión de bienes de uso doméstico -a cargo del Estado-, entre los que se encontraban los alimentos, por lo que se ocasionó también una delicada situación humanitaria.
Aunque para 1995 se establecieron algunas medidas de apertura para paliar la crisis, por ejemplo, el fomento a la inversión extranjera o el desarrollo de algunas iniciativas privadas nacionales, la economía siguió siendo planificada y con una permanente intervención del Estado, siempre con una profunda desconfianza hacia el reconocimiento de la propiedad privada y la posibilidad de enriquecimiento particular por parte de sus habitantes. Si bien las medidas no fueron efectivas en el corto plazo, el establecimiento de nuevos destinos de las exportaciones, por un lado, y la entrega de cooperación económica, representada en ayuda y préstamos por la Unión Europea, por otro, -sin contar la asistencia que el gobierno venezolano empezó a dar a la isla con la llegada al poder de Hugo Chávez- mejoraron un poco la situación, sin embargo las condiciones del cubano promedio continuaron siendo bastante precarias, atadas a un conjunto de restricciones que superaban el ámbito económico financiero y se extendía a los derechos civiles y políticos y al acceso a bienes de consumo y/o servicios de común uso en los demás países de la región. Como si fuera poco, la precariedad de muchos productos provistos por el Estado siguió siendo la regla general.

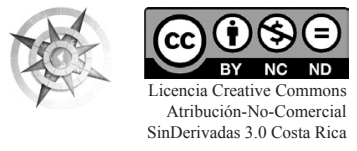


No obstante, desde mediados de la década del 2000 se inició una serie de medidas dirigidas, en primer término, a la recuperación definitiva de la economía cubana, y luego, a mejorar el nivel de vida promedio del cubano residente. Las medidas tuvieron dos carices: por una parte, promovieron la autosuficiencia de Cuba (cual fue una política generalizada desde el triunfo de la Revolución) en sectores como el energético (especialmente el de la energía eléctrica), y por otra parte, constituyeron acciones de apertura económica, con el propósito de aumentar la inversión foránea, las cifras de intercambio comercial y la capacidad adquisitiva de sus habitantes.

El cambio de mando en Cuba, a partir del retiro definitivo de Fidel Castro y la asunción del poder por su hermano Raúl en el 2006, significó una profundización de la senda aperturista. Sin embargo, en materia de derechos civiles y políticos, la isla continúa siendo bastante restrictiva y el Estado aún ejerce un fuerte control sobre los medios de comunicación. Inclusive, la libertad económica permanece bastante restringida y a menudo son revocadas o matizadas acciones que habían sido establecidas en beneficio de los residentes cubanos.
Lo anterior lleva a preguntarse si las medidas de apertura tomadas por el Estado cubano tras el Período Especial de los años 1990 apuntan a una liberalización general de la economía que pueda generar cambios en el régimen político, o si por el contrario, apenas buscan generar una economía "a la china" o "a la vietnamita" en la que se mantenga el sistema de partido único y el Estado siga ejerciendo un amplio control sobre la actividad económica. La respuesta a este interrogante estará dada por la medición del impacto de las medidas aperturistas adoptadas por el gobierno de Cuba durante los últimos once años y sus efectos sobre el crecimiento y el desarrollo económico del país durante el último y el próximo lustro.

Con miras a los objetivos propuestos, el presente trabajo partirá de un enfoque comparativo, que confronte algunas cifras generales de la economía cubana en el momento de la Revolución frente a las presentadas durante la caída del socialismo real y las resultantes como consecuencia de la primera ola de reformas, buscando un patrón de cotejo que, por lo tanto, permita estandarizar indicadores de diferentes épocas. $\mathrm{Al}$ respecto, es preciso señalar con antelación que la negatividad de las cifras en las últimas décadas es la

46 Nuevos vientos soplan en el malecón de La Habana: Reformas económicas y cambio político en Cuba Jhany Marcelo Macedo Rizo 
que sustenta la adopción de medidas legales que buscan repercusiones en el ámbito económico, por lo que la posición del Estado cubano en este sentido ha de ser considerada como reactiva, llegando incluso a la modificación posterior de reformas ya implementadas, en tanto sus logros fueron limitados en relación con las expectativas generadas por las normas originales. Desde un punto de vista estrictamente jurídico, puede sostenerse que el proceso reformista en Cuba asume un enfoque instrumentalista, por el que a través de la introducción de reglas busca producirse un cambio en la realidad, a manera de efectos producidos "desde afuera", perspectiva que se contrapone a la construccionista, que por su parte pregona que las normas deben ser resultado de la realidad social y, en consecuencia, erigidas "desde abajo". En todo caso, la capacidad de transformación que estas últimas tengan en la vida material de los cubanos dependerá en buena medida, como ya se aludió, de la eficacia en sus resultados.

En aras de dilucidar la cuestión planteada y alcanzar satisfactoriamente sus propósitos, el presente trabajo se dividirá en tres partes: en la primera de ellas se hará una revisión general de algunas cifras económicas de Cuba desde el triunfo de la
Revolución (1959) y los fenómenos externos que incidieron en su economía nacional, con el fin de determinar las causas estructurales que dieron pie a las medidas que se han introducido desde finales del Período Especial (1991-1997) y en particular a partir de 2007. En la segunda parte, se ahondará un poco en la naturaleza de las más importantes reformas económicas adelantadas por Cuba en los últimos años, llevando a cabo una descripción y breve análisis de estas. Aunque tiene un carácter prevalentemente político, también se hará alguna referencia al reciente restablecimiento de relaciones diplomáticas con los Estados Unidos, así como a las nuevas restricciones promovidas por ese país, en razón a las repercusiones comerciales que este hecho pueda tener sobre Cuba. Finalmente, se evaluarán los posibles efectos que dichas reformas pueden tener tanto sobre la economía cubana como sobre el régimen político de la isla.

\section{Breve revisión de la economía cubana entre 1959 y 2008}

Para el año 1958, Cuba contaba con importantes cifras en materia de "PIB por habitante, control de la inflación, estabilidad fiscal, alfabetización, mortalidad infantil, esperanza de vida y cobertura de pensiones"

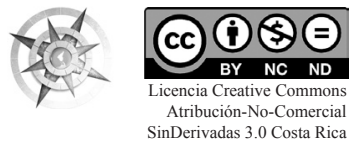


(Mesa-Lago, 2009: 42), aunque también sufría de graves problemas económicos relacionados principalmente con una tasa de crecimiento reducida, un sector azucarero estancado -a pesar de la alta dependencia de su economía respecto de este producto-, elevadas cifras de desempleo, una gran diferencia en las condiciones de la población rural frente a la urbana y una notable influencia de los Estados Unidos en su economía, como principal socio comercial.

Con el advenimiento de la Revolución en 1959, se introdujeron importantes cambios en las relaciones de propiedad, a través de la nacionalización de los principales medios de producción y de los bancos. Además, luego de que se declaró el carácter socialista de la experiencia revolucionaria, se adoptó un régimen de economía planificada, organizada conforme a ciclos temporales con objetivos determinados de política macroeconómica. Como lo señalan Odriozola Guitart y otros, la planificación se contrapone al mercado en tanto forma fundamental de regulación de la actividad económica, en la cual el Estado ejerce una regulación directa de la economía, "a través de la asignación de tareas y recursos de acuerdo con un plan central, aplicable principalmente a las unidades económicas que se encuentran bajo formas de propiedad social" (en: García Rabelo e Hidalgo de los Santos, 2013: 18). La planificación de la economía abarca entonces, por una parte, la dirección por el Estado de las políticas macroeconómicas, las cuales abordan cuatro problemas fundamentales: la producción de bienes y servicios, el desempleo, la inflación y el equilibrio externo, "que muestra el balance de las relaciones comerciales y financieras del país con el resto del mundo" (ibíd., 65). El tratamiento de estos problemas se realiza principalmente por medio de i) la política monetaria y cambiaria, en cabeza del Banco Central; ii) la política fiscal, que busca una adecuada "utilización de los instrumentos fiscales (impuestos, subsidios y gasto público) para incidir en el nivel de producción y empleo de la economía (ibíd., 76); y iii) la política de precios. Por otra parte, la planificación depende de una política de inversiones, entendidas estas como la reducción del "consumo en el presente para lograr el incremento del consumo en el futuro" (ibíd., 84) y que depende fundamentalmente de la disponibilidad de recursos financieros para la adquisición de medios que permitan ampliar las capacidades productivas y de servicios.

48 Nuevos vientos soplan en el malecón de La Habana: Reformas económicas y cambio político en Cuba Jhany Marcelo Macedo Rizo 
Como lo demuestra Mesa-Lago, al comparar los indicadores internos cubanos de 1958, con los de 1989 y finalmente con los de 2007 y $2008^{1}$, la mayoría de estos sufrieron una importante contracción para finales de los años 1980, previo a la caída del bloque socialista, y para el último período demuestran un evidente deterioro. De ellos, los más representativos fueron la reducción del PIB por habitante en una tasa de $-15 \%$ en comparación con cincuenta años atrás, de $-55 \%$ respecto de la formación bruta de capital, aumento de $390 \%$ en la tasa de inflación y de cifras negativas en casi toda la producción, con la salvedad de productos minerales (níquel, petróleo, gas natural), del acero y de los puros, que presentan comportamientos positivos (Mesa-Lago, 2009: 46).

En referencia a los indicadores del sector externo, el aumento en el volumen de exportaciones desde el año previo a la Revolución, en contraste con el 2007 , fue de $211 \%$, pero comparado con las cifras de 1989, hubo una reducción del 35\%. Para el último año de medición (2008) se

1 Para lograr una adecuada comparación, el autor acude a métodos normalizados internacionalmente para medir el desarrollo socioeconómico de los países, que a menudo chocan con las cifras oficiales del gobierno cubano, el cual no sigue los patrones internacionales de medición, o bien, no publica estadísticas. observa un déficit en la balanza del 850\% del PIB en relación con 1958 y de $111 \%$ frente al mismo indicador en 1989. En este sector, los números más importantes se encuentran, por un lado, en el aumento significativo de la deuda, que para el 2008 constituye el 32\% del PIB, y por otro, en el turismo, que no solo ha tenido un importante incremento del $490 \%$ en el 2008 en comparación con 1958 y de 704\% frente a 1989 (ibíd., 49), sino que representa el mayor ingreso bruto por habitante, consolidándose como un eje fundamental de la economía cubana. En cuanto a socios comerciales, para 1958 los Estados Unidos copaban el $62 \%$ del comercio exterior de Cuba, cifra parecida al $65 \%$ que se sostenía con la URSS en 1989, y que para el 2008 denota una mayor diversificación, pues su principal socio, Venezuela, ocupa apenas el 20\% (ibíd., 50).

El apoyo de Venezuela jugó un importante papel en la primera década del siglo XXI, tiempo durante el cual brindó asistencia a Cuba "a través de tres canales principales: las ventas de petróleo a pagos diferidos y subsidiados, los acuerdos de inversión mediante los cuales el gobierno de Venezuela financia proyectos de desarrollo en la isla y la adquisición de servicios de salud" (Castañeda, 2009: 396). Este elevado nivel de

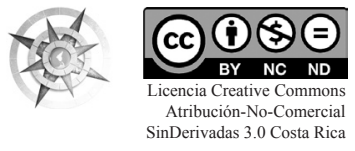

Nuevos vientos soplan en el malecón de La Habana: Reformas económicas y cambio político en Cuba 
ayuda tuvo un sustento político, fincado en la afinidad ideológica que el presidente Chávez encontró con el gobierno cubano, y otro económico, facilitado por los altos precios del petróleo durante la década referida, los cuales alcanzaron su nivel récord histórico en el 2008.

No obstante, como lo advierte Mesa-Lago, "el enorme déficit presupuestario que se proyecta en Venezuela crea fuertes presiones para reducir su ayuda y subsidios a Cuba. A pesar de los esfuerzos por diversificar sus socios comerciales (con China, Rusia, Brasil) la dependencia con Venezuela es muy fuerte y Cuba podría enfrentar un segundo Período Especial si se termina o reduce considerablemente la ayuda venezolana" (2009: 51). Castañeda comparte esta preocupación cuando recalca: "Cuba está dependiendo mucho de Venezuela que está desarrollando un sistema económico similar al cubano, que es muy ineficiente y que tarde o temprano será insostenible" (2009: 396). En su opinión, Cuba, para esta época estaba apostándole nuevamente a consolidar un socio prevalente, lo que incrementaba su vulnerabilidad. Esta quizá sea una de las razones de las medidas de apertura que se adoptaron en los últimos años.
Pero, aparte de los indicadores económicos para realizar un análisis integral es necesario también revisar los indicadores sociales, a los que Mesa-Lago aplica los mismos criterios comparativos, encontrando una profunda reducción en el salario real $(-76 \%)$ entre 1989 y 2007, al igual que una disminución del $62 \%$ de la pensión media real, pero a la vez un porcentaje similar en la reducción de la tasa de desempleo declarado. Por el contrario, los indicadores de educación y sanidad son positivos, con una tasa de alfabetización cercana al $100 \%$ y con participación del $88 \%$ de la educación superior, una cobertura de salud universal, así como un importante número de médicos (64) por cada mil habitantes (Mesa-Lago, 2009: 53). Todo lo anterior lleva al autor a concluir que "se ha demostrado que en los últimos cincuenta años Cuba sufrió un severo deterioro económico (particularmente interno, que a su vez afectó al sector externo), acentuado bajo el Período Especial. Respecto a los indicadores sociales, la gran mayoría de ellos mejoró pero en el 2008 la mitad aún no había recuperado los niveles de 1989" (ibíd., 59). De allí que recomiende que "para mejorar el pobrísimo desempeño económico es primordial avanzar en las reformas estructurales anunciadas por Raúl Castro, mientras que los

50 Nuevos vientos soplan en el malecón de La Habana: Reformas económicas y cambio político en Cuba Jhany Marcelo Macedo Rizo 
beneficiosos pero costosos servicios sociales deben hacerse sostenibles financieramente a largo plazo" (ibíd.).

Ahora bien, pese a las poco halagadoras cifras que se presentan, vale la pena mencionar que estas no han obedecido completamente a una equivocada estrategia de planificación de la economía, sino que en la permanente crisis cubana han tenido influencia otros factores externos que han impedido un mayor desarrollo y han representado un objeto de inestabilidad y sabotaje a los intentos de apertura del régimen cubano. Uno de estos elementos es sin duda el bloqueo económico por parte de los Estados Unidos, que tuvo inicio en 1961, con aplicación de la llamada Ley de Asistencia al Extranjero, en cuya enmienda, como lo recuerdan Pardo Martínez y Valdés Lobán, "se estableció la negativa de toda asistencia al gobierno de Cuba y la autorización para que el Presidente de los Estados Unidos fijara y mantuviera el embargo total del comercio entre Cuba y EEUU" (1999: 2). Como ya se resaltó, para el año precedente al triunfo de la Revolución, el país del norte era el principal socio comercial de Cuba, con un $62 \%$ de participación, generando un impacto negativo inmediato y propiciando la búsqueda de nuevos socios en el bloque socialista, lo que llevó a que la Revolución, que en un principio tenía carácter agrario (en este sentido, más parecida a la Revolución Mexicana que a la Bolchevique, ambas de principios del siglo XX) y nacionalista, fuera declarada finalmente socialista, con todas las repercusiones que este hecho tuvo en el contexto de la Guerra Fría para el futuro de la isla.

Esta es la tesis que defienden Haney y Vanderbush, cuando afirman que "cuando Cuba se movió hacia adentro de la esfera soviética y el embargo tomó forma, este se vio embebido en la política de la Guerra Fría" (2005: 11). Así se pasó de tener a los Estados Unidos como principal aliado comercial a tener a la URSS como mayor apoyo. Sin embargo, la transición en términos económicos no fue rápida ni en el volumen esperado, sin poder alcanzar los niveles nominales de intercambio que se tenían con el vecino del norte. El trasfondo político y estratégico del bloqueo a Cuba se explica entonces en este contexto y si bien el conflicto bipolar desapareció hace más de un cuarto de siglo, varias de las medidas contra la isla se mantienen, tornándose anacrónicas. Para White, los motivos expuestos en el inicio por el gobierno norteamericano para impulsar el bloqueo se basaban en actuaciones aparentemente ilegales de la Revolución, pero que tras el fin de

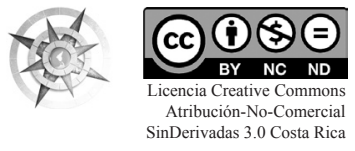


la Guerra Fría y mucho más en la actualidad han perdido por completo ese fundamento, obedeciendo únicamente a una disonancia de identidad política, originada en las distintas visiones del modelo económico. Como él mismo lo señala, "aunque las razones originales para la imposición de medidas por los EEUU en 1960 incluían responder a violaciones del derecho internacional por el gobierno revolucionario cubano, su mantenimiento luego de cinco décadas aparece casi exclusivamente como una cuestión de ideología y política" (White, 2015: 1).

Pero además de la Ley de Asistencia al Extranjero, el bloqueo también tuvo fundamento en otras normas de posterior creación, como lo fueron la Ley de Administración de Exportaciones y las Regulaciones sobre importaciones cubanas de 1979, que buscó restringir las exportaciones de Cuba hacia países aliados del hegemón norteamericano; y la Ley Torricelli (o para la Democracia en Cuba) de 1992, que estableció cuatro limitadas excepciones al férreo bloque comercial a la isla, relacionadas con que el gobierno de los Estados Unidos tuviera la posibilidad de verificar mediante medios apropiados que los artículos exportados hacia Cuba cumplirían con sus propósitos originales y serían exclusivamente para uso y beneficio de los residentes en la isla. Esto incluía cotejar que los productos llevados a territorio cubano no fueran reexportados hacia otros países, que no se emplearan en la fabricación de elementos biotecnológicos, o que, de acuerdo con las razones primigenias de las medidas, que buscaban sancionar violaciones del gobierno revolucionario contra el derecho internacional, dichos bienes no pudieran ser utilizados para la comisión de ilícitos tales como la tortura. En la práctica, esta última restricción dificultó el acceso a instrumentos médicos.

Con posterioridad, surgió la Ley Helms-Burton (o para la Libertad y Solidaridad Democrática Cubana) de 1996, la cual impuso un bloqueo internacional obligatorio contra Cuba, previendo fuertes sanciones a los países de la antigua Cortina de Hierro que brindaran ayuda económica al Estado cubano o brindaran "apoyo logístico y financiero a personas y ONG que promovieran la oposición al gobierno de La Habana" (Pardo Martínez y Valdés Lobán, 1999: 11). Esta norma fue reformada por la denominada Ley de Sanciones Comerciales e Incremento del Comercio, más conocida como Ley TSRA por sus siglas en inglés, que en el 2000 flexibilizó un poco el embargo mediante la autorización a la venta

52 Nuevos vientos soplan en el malecón de La Habana: Reformas económicas y cambio político en Cuba Jhany Marcelo Macedo Rizo 
de productos agrícolas y medicinas a Cuba por razones humanitarias.

Así las cosas, el aislamiento generado por el bloqueo, aunado a la disolución de la URSS y los problemas internos de la economía cubana, visibles durante todo el transcurrir de la Guerra Fría, con el consecuente acaecimiento del Período Especial, suscitaron sin duda un ambiente de reforma, que solo vino a darse a fondo algunos años después.

\section{Las reformas económicas tras el Período Especial}

Los antecedentes inmediatos que obligaron a la introducción de reformas en Cuba se encuentran sin duda en la caída del bloque soviético más la situación de crisis interna causada por la política económica de la Revolución y por el bloqueo. Como se resaltó con anterioridad, para 1989 la URSS constituía el principal socio comercial de Cuba, ocupando el 65\% del sector externo de la isla, mediante una relación bidireccional que comprendía, por un lado, la compra de la mayoría de los productos cubanos, y por otro, amplios paquetes de ayuda económica, que supusieron la estabilidad económica, aunque con poco crecimiento, de Cuba. La desintegración de la antigua Unión Soviética, aparejada al derrumbe del socialismo real en Europa del Este y la transición democrática con orientación económica neoliberal de los demás países de América Latina y el Caribe, aunado al bloqueo que restringió las posibilidades de intercambio comercial con otros países, condenaron a Cuba a un aislamiento sin precedentes, traducido en una fortísima contracción económica, que en un país de economía planificada y con alto contenido de políticas sociales, conllevó a un dramático deterioro de la calidad de vida. Este período de profunda crisis se conoce con el nombre de Período Especial, que si bien en términos prácticos (de baja producción, crecimiento estancado, merma significativa en la provisión de bienes y servicios básicos a la población), se mantuvo hasta principios del siglo XXI, oficialmente se extiende hasta 1997, año para el cual ya se habían empezado a implementar las primeras medidas introducidas tendientes a paliar sus terribles efectos. Es por esto que, en materia de reformas, las que se han presenciado en Cuba durante las últimas dos décadas pueden dividirse en dos grupos: las primeras, que se comprenden en el espacio de tiempo que va de 1995 al 2005; y las segundas, que acontecen con ocasión de la llegada al poder de Raúl Castro ante el retiro de su hermano

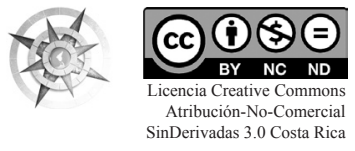

Nuevos vientos soplan en el malecón de La Habana: Reformas económicas y cambio político en Cuba 
Fidel, y que se extienden desde el 2007 hasta el 2015.

\section{1995-2005. Aunque para 1993} se legalizó el uso y la tenencia de dólares americanos, en un intento desesperado por hacer frente al Período Especial $^{2}$, muy pronto se intentó fortalecer la política monetaria en la isla, por medio de la disposición de un mayor control efectivo de la circulación. Por este motivo, en 1994 se introduce el Peso Cubano Convertible (CUC), cuyo funcionamiento, como lo señala García Molina, "ha sido parecido a la caja de conversión (Currency Board) de otros países, mediante la cual el efectivo en circulación está respaldado en su totalidad por reservas internacionales" (2005: 7). En su opinión, "esta medida garantizó estabilidad cambiaria de un dólar estadounidense equivalente a un peso convertible en el territorio nacional en un contexto donde no existe un mercado monetario informal" (Ibíd.). La introducción del CUC vino acompañada de la creación de redes de casas de cambio, para

2 Hasta 1993, la tenencia y circulación de divisas estaba prohibida en Cuba, a pesar de que la población acumulaba buena cantidad, como producto de remesas, turismo o vínculos con entidades extranjeras. La imposibilidad de hacer uso de ellas y la necesidad de utilizarlas para fines sociales precipitó la reforma a la que se hace referencia. realizar transacciones entre pesos convertibles y divisas y en general ejecutar todo tipo de transacciones financieras en las que estuvieran involucradas monedas extranjeras.

Con la autorización de apertura de cuentas de ahorros en dólares, y en un ambiente generalizado de descentralización económica, en 1997 se llevó a cabo una reestructuración del sistema financiero cubano, mediante la separación de la banca central (ahora en cabeza del Banco Central de Cuba) y la creación de bancos e instituciones financieras no bancarias, estando ambas (banca central y comercial) hasta ese momento bajo la dirección de una sola entidad. De acuerdo con el Decreto Ley que reguló la nueva banca comercial, "las instituciones financieras pueden constituirse como entidades estatales y como entidades no estatales en forma de sociedades anónimas" (ibíd., 56), lo cual significó una importante medida de apertura, aunque con participación limitada de capital privado y extranjero hasta el porcentaje permitido por el $\mathrm{BCC}$, que por lo general nunca fue superior al $49 \%$, con el fin de que el Estado siguiera teniendo el control de dichas instituciones. Como bien lo destaca el autor en mención, estas reformas institucionales estuvieron "encaminadas a enfrentar problemas estructurales

54 Nuevos vientos soplan en el malecón de La Habana: Reformas económicas y cambio político en Cuba Jhany Marcelo Macedo Rizo

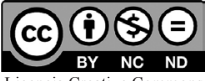

Licencia Creative Commons Atribución-No-Comerci SinDerivadas 3.0 Costa Rica

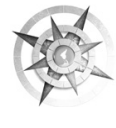


de la economía cubana como la escasez de divisas que reduce la capacidad de maniobra de la política económica, la dualidad monetaria y de precios, la sobrevaluación oficial de la moneda nacional y la ausencia de su convertibilidad" (ibíd., 36). A pesar de los aparentes beneficios que la creación del CUC generó para la economía cubana, se prevé que la dualidad de monedas desaparezca pronto con el fin de restablecer el "valor del peso cubano y de sus fun-

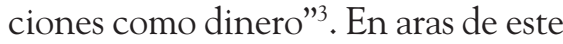
propósito, en octubre del 2013 el gobierno de Cuba determinó una hoja de ruta para la eliminación del CUC y la unificación monetaria, cuya fecha inicial estaba prevista para el 2015, luego se aplazó para el 2017 y lo más probable es que se difiera hasta el 2019, aunque el plazo sigue siendo incierto. De cualquier forma, el restablecimiento de relaciones diplomáticas entre Cuba y los Estados Unidos a mediados de 2015 ha incrementado significativamente el turismo y el flujo de divisas a la isla.

En medio de las dos reformas mencionadas (CUC y sistema financiero), se promulgó en 1995 la Ley de Inversiones Extranjeras, que sería objeto de

3 Intervención del Vicepresidente de Cuba, Marino Murillo, ante el XX Congreso de la Central de Trabajadores de Cuba (CTC), que tuvo lugar en La Habana, durante el mes de febrero del 2014. diversas modificaciones posteriores, como se verá más adelante. Esta ley "abría la puerta a la participación del capital foráneo en todas las actividades de la economía, con excepción de la educación, la salud y la defensa, (...) se ponía fin a la discriminación de los inversionistas por su origen y se autorizaban las transferencias al exterior libres de impuestos y las operaciones de comercio internacional" (Palacios Cívico, 2012: 33). Por otro lado, para el año 2000 se aprobó en los Estados Unidos la enmienda TSRA a la Ley Helms-Burton que permitió el abastecimiento de alimentos y bebidas a la isla por parte de empresas norteamericanas.

Al margen de los avances registrados, valga señalar que el gobierno cubano para el momento continuaba defendiendo un modelo económico socialista basado en la planificación centralizada, pero "asume la utilización de relaciones monetario-mercantiles, mercados regulados y un sistema de gestión empresarial progresivamente descentralizado en su funcionamiento" (CEPAL, 2000: 99). En este sentido, como lo anota Virgili, "se aceptan cambios orientados hacia el mercado en tanto se asume una mayor eficacia en términos de asignación de recursos, pero se rechaza de manera categórica la primacía de este mecanismo sobre el conjunto de

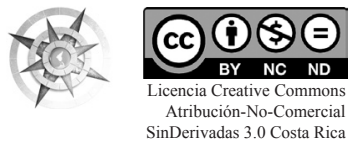


la economía" (2007: 82). Habrá que ver si las medidas del nuevo siglo siguen esta orientación o si realizan un acercamiento más significativo hacia la economía de mercado.

Al evaluar los resultados de esta primera etapa de reformas, se observa que, según la CEPAL, la economía cubana creció a un promedio de $3.2 \%$ entre 1997 y 2003 , siendo una tasa inferior a las registradas antes de 1989, pero muy por encima de las presentadas durante el Período Especial, cuando el PIB cayó a niveles de hasta -35\% (Virgili, 2007: 86). Estas cifras se contraponen a las ofrecidas por Mesa-Lago quien, como se vio, estableció que para el 2003 los indicadores eran inferiores a los observados a finales de los años 1980. Aunque en términos generales, hubo un mejoramiento respecto de los números que se dieron durante la crisis, el crecimiento y la calidad de vida continuaron muy estancados.

2.2007-2015. Con el retiro definitivo de Fidel Castro de sus funciones gubernamentales y la llegada de Raúl a la presidencia de Cuba, se inició un nuevo ciclo reformista. Aunque desde su discurso de posesión advirtió que sería un continuador de la obra de la Revolución, también afirmó que "para enfrentar la crisis de la economía cubana eran necesarias reformas estructurales y de concepto" (Mesa-Lago, 2012: 23). Al respecto, desde el punto de vista teóri$\mathrm{co}$, es indispensable señalar que los cambios en el funcionamiento de la economía cubana se plantearon empero cinco años más tarde de manera determinante en los Lineamientos de la Política Económica y Social del Partido y de la Revolución, aprobados en el VI Congreso del Partido Comunista de Cuba, en abril del 2011. Este marco de actualización del modelo económico cubano prevé continuar "la aplicación de medidas encaminadas a fortalecer el funcionamiento del sector no estatal de la economía, a dinamizar el sector agrícola, a crear las bases para el perfeccionamiento de la gran empresa estatal, el desarrollo de las cooperativas urbanas, el estudio de la implementación de los mercados mayoristas, a la conceptualización del futuro modelo económico cubano, entre otras" (Pérez Villanueva y Torres Pérez, 2013: 1). Los Lineamientos estuvieron acompañados de una importante reforma institucional, por la cual se eliminaron algunos ministerios y se crearon otros nuevos, además de que se reorganizaron múltiples instituciones nacionales y regionales, tales como la Contraloría General de la República, encargada del control y la supervisión de los recursos estatales. Como lo señala Torres Pérez, "el

56 Nuevos vientos soplan en el malecón de La Habana: Reformas económicas y cambio político en Cuba Jhany Marcelo Macedo Rizo 
objetivo declarado de la propuesta actual está en lograr un modelo económico que garantice el incremento de la productividad, la eficiencia y la competitividad necesarios para continuar sosteniendo el actual sistema de prestaciones sociales" (en: ibíd., 40). A juicio de Palacios Cívico, las reformas además buscan mejorar el ambiente microeconómico y de incentivos, "lo que a su vez debe coadyuvar a la expansión de las capacidades productivas y a la mejora del equilibrio de la balanza de pagos" (2012: 49).

Ahora bien, en términos prácticos, siguiendo a Mesa-Lago, las reformas en la era de Raúl Castro se pueden clasificar en tres grupos: 1) medidas administrativas, destinadas a mejorar la eficiencia en la gestión; 2) cambios no estructurales, que, sin modificar la esencia del modelo, eliminan exclusiones y prohibiciones anteriores; y 3 ) reformas estructurales, destinadas a modificar "las bases materiales y organizativas del funcionamiento de la economía" (Mesa-Lago, 2012: 237). Entre las primeras se pueden mencionar la Ley de Perfeccionamiento Empresarial, la lucha contra la corrupción y la apertura a la crítica.

Entre los cambios no estructurales se pueden enumerar, por ejemplo, el acceso a sitios turísticos de los ciudadanos cubanos, que estuvo prohibido hasta el 2008, la autorización para crear empresas privadas de transporte y, en general, la expansión del trabajo por cuenta propia y no estatal, que significó un paso de 150.000 trabajadores cuentapropistas en el 2011 a casi medio millón en el 2016. "Así el empleo en el llamado sector no estatal -que incluye al sector privado y el cooperativoaumentó del 16,2\% del total de trabajadores al $27 \%$. Sin embargo, su aporte al PIB se mantuvo en el 12\%" (Rodríguez, 2013), por lo que si bien se ha convertido en una importante fuente de vinculación para los cubanos, mantiene un bajo nivel de flujo de capital y, en consecuencia, no ha permitido "los recursos de inversión suficientes para convertirse en el sector que arrastre el crecimiento del país" (ibíd.).

En el segundo grupo de medidas también se encuentran los permisos para la apertura de pequeños negocios propios -dedicados en especial a la provisión de servicios turísticos-, el aumento de los salarios, la gradual eliminación de gratuidades y subsidios y, primordialmente, la propuesta de supresión de la dualidad monetaria orientada al aumento de la capacidad adquisitiva real del cubano promedio. Estos cambios están

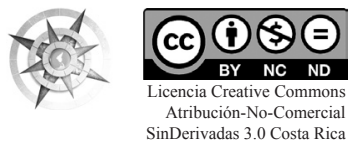


complementados por medidas como la nueva ley tributaria del 2012, que les otorga una mayor participación a los impuestos dentro de los recursos financieros del presupuesto nacional y que se concibe como un mecanismo para la redistribución de los ingresos en la sociedad; la nueva política crediticia, que abre la posibilidad del crédito a los trabajadores por cuenta propia, a los agricultores y "a quienes requieran hacer acciones constructivas en sus viviendas o consumir bienes materiales" (Pérez Villanueva y Torres Pérez, 2013: 87) y la reforma laboral, que eliminó 500.000 empleos estatales en el 2011, "con miras a la incorporación de más de 1,8 millones de trabajadores (de una fuerza de trabajo total estimada de 5,3 millones) al sector privado en 2015" (Sweig y Bustamante, 2013: 98).

Finalmente, en cuanto a las reformas estructurales, se pueden resaltar la entrega de tierras en usufructo para estimular la explotación de la tierra cultivable inactiva (aunque se espera que la participación privada en el sector agrícola llegue al $80 \%$ de las tierras aptas para el cultivo), y un nuevo marco heterogéneo de la propiedad, en el que si bien la "empresa estatal continúa siendo la forma predominante, por primera vez se brinda la posibilidad de que el sector no estatal integre el paisaje productivo del país, por derecho propio y con un espacio definido" (Pérez Villanueva y Torres Pérez, 2013: 41). Además, el levantamiento progresivo de limitaciones al consumo, la creación de un mercado limitado de activos y el estímulo al consumo privado por encima del social, resultan modificaciones de fondo en la concepción tradicional de la economía cubana, acompañadas de otras medidas que significan una ampliación de los derechos y las libertades civiles. Ejemplos de esta nueva apertura "democrática" lo constituyen el acceso general reciente a teléfonos celulares, el levantamiento en la restricción a los viajes fuera del país y la rehabilitación de rutas aéreas desde los Estados Unidos como consecuencia del restablecimiento de las relaciones diplomáticas entre ambos países, la recepción sin limitaciones de remesas, la expansión del acceso a Internet y el permiso para la creación de medios alternativos (no oficiales) de comunicación, entre otros.

Si bien el nuevo inicio de la relación bilateral entre Cuba y Estados Unidos en julio del 2015 podría considerarse una de las reformas (inclusive de las estructurales) para mejorar el desempeño de la economía cubana, teniendo en cuenta el impacto

58 Nuevos vientos soplan en el malecón de La Habana: Reformas económicas y cambio político en Cuba Jhany Marcelo Macedo Rizo 
comercial que este evento ha tenido -especialmente en el campo del turismo y que se espera ampliar pronto a los sectores de las telecomunicaciones y la agroindustria- por ser de trasfondo político y debido a las nuevas restricciones impulsadas por la administración Trump, cuyos efectos económicos aún no pueden ser dilucidados, no será incluido en el grupo reconstruido dentro del presente texto. Con todo, sus consecuencias en el mediano plazo sí serán un objeto interesante de estudio que podrá evidenciar su complemento a las medidas del segundo ciclo forjadas en la última década bajo la presidencia de Raúl Castro, cuyo retiro, en abril de 2018 , puede abrir las puertas a una nueva ola de reformas.

\section{Efectos sobre la economía y el régimen político cubanos}

La principal evaluación de las medidas que se han venido adoptando en los últimos veinte años, pero que se han intensificado desde el 2006 -con el cambio de gobierno-, y especialmente desde el 2011, luego del VI Congreso del Partido Comunista, obedecerá sin lugar a dudas al mejoramiento de las cifras económicas de Cuba (tanto en su sector interno como externo), en general, y de las condiciones de vida de los cubanos residentes en la isla, en particular. Empero, el éxito o fracaso de estas también estará medido por el margen de la ampliación o restricción de las libertades civiles y políticas, esto es, por la capacidad o disposición que tenga el gobierno cubano de permitir a sus ciudadanos el ejercicio de derechos democráticos de tinte liberal; y lo más importante, por la resolución del dilema entre el sostenimiento de un modelo económico de fuerte intervención estatal o el encaminamiento definitivo hacia una economía de mercado, aunque de manera gradual o con las restricciones que el régimen político imponga. Se establece así una relación bidireccional en la cual entran en juego tanto el carácter de las instituciones políticas y económicas que regirán en la isla durante los próximos años, como la posibilidad de salida decisiva del estancamiento económico y la crisis generalizada, dependiendo aquellas más de esta que al contrario. Es por eso que resulta pertinente regresar sobre una inquietud que se planteó al principio de este trabajo, relacionada con las consecuencias que tendrán estas recientes reformas sobre el Estado cubano, en el sentido de si persiguen (y provocarán) una liberalización general de la economía o si más bien buscan emular el modelo chino (o vietnamita), con un sistema político unipartidista y

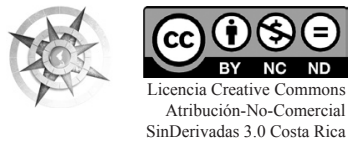


todavía un gran control por parte del Estado en el desenvolvimiento de la vida económica del país. Quizá las líneas subsiguientes puedan arrojar luces al respecto.

En su diagnóstico e intento de proyección de las reformas acontecidas en los últimos años en Cuba, Alonso y Vidal resaltan la cada vez mayor tasa de empleo dependiente del sector cuentapropista y cooperativo, con una correlativa disminución de la ocupación en empresas y organizaciones estatales. No obstante, como oportunamente lo señalan, "en contraposición a la liberalización que ocurre en el sector privado y cooperativo, la asignación y control de los recursos en la empresa estatal se sigue apoyando en la planificación centralizada (...) En esencia, el modelo económico de asignación de recursos típico de un país socialista se conserva y se refuerza en muchos aspectos, a pesar de la acumulada evidencia que existe cuestionando su eficiencia" (2013: 14). Aunque reconocen que las reformas han llevado "a la eliminación de absurdas prohibiciones a las cuales estaban sujetos los ciudadanos cubanos" (ibíd., 15), se muestran cautelosos frente a la posibilidad de que las medidas que se vienen adoptando conduzcan a un ámbito de mayores libertades públicas, y aun de importantes resultados económicos, a partir del planteamiento de los enormes desafíos que se presentan a la economía cubana en los años venideros. En su criterio, el objetivo más difícil que tiene por delante el proceso reformista es la eliminación de la dualidad monetaria, debido a la necesidad que tiene el Banco Central de propiciar una convergencia de los tipos de cambio y las posibles consecuencias que este ajuste tendrá sobre fenómenos como la inflación, las cuentas fiscales y los balances de empresas y los demás bancos. De allí que indiquen que "la convergencia de los tipos de cambio permitirá que afloren los verdaderos focos de ineficiencia del modelo, hoy ocultos tras la circulación paralela de dos monedas" (ibíd.).

Además de la unidad monetaria, los desafíos de las reformas también se encuadran, en primer término, en la generación de un crecimiento sostenido. Sin embargo, a juzgar por los resultados, con un aumento promedio de apenas 2,75\% del PIB en el período 2007-2012, de 2,66\% entre el 2013 y el $2015,0,5 \%$ en el 2016 y $1,6 \%$ en el 2017 , muy por debajo de las previsiones oficiales, las expectativas no resultan muy halagadoras. En segundo lugar, se torna indispensable la búsqueda de nuevos socios comerciales y una diversificación

60 Nuevos vientos soplan en el malecón de La Habana: Reformas económicas y cambio político en Cuba Jhany Marcelo Macedo Rizo 
de la oferta exportadora, para hacer frente a la reducción del intercambio con Venezuela, pues la alta dependencia respecto de su socio en Sudamérica "da la idea de la vulnerabilidad de la economía a un cambio de las circunstancias de la economía o la política de aquel país latinoamericano" (ibíd.). En este sentido, la profunda crisis venezolana, palpable desde el 2014, representa una amenaza para el sector externo de Cuba.

Finalmente, otro de los retos que encuentran los autores referidos tiene que ver con el cambio generacional en la dirección del país que necesariamente tendrá que darse durante los siguientes años. Al respecto, critican la incapacidad que han tenido los políticos "octogenarios" para facilitar una transición en el poder hacia los más jóvenes y para garantizar la continuidad en el proceso reformador.

En un enfoque similar al de Alonso y Vidal, Mesa-Lago también sostiene que las decisiones del nuevo esquema "no transforman sustancialmente el modelo actual sino que proponen actualizarlo en forma gradual y programada" (2012:253), por lo que aún se "mantienen trabas y desincentivos que restringen su efectividad para resolver problemas" (ibíd.). De todos modos, reconoce que este ha sido el intento más avanzado y el proceso de reforma más profundo que ha tenido el modelo socialista de la isla desde que triunfó la Revolución, pero propone que la acentuación de las medidas de apertura y liberalización es la forma en que la crisis permanente podrá ser finalmente superada. De allí que abogue por un abandono del modelo de planificación estatal, por la reducción en el predominio de la empresa estatal, por la mayor participación de la inversión privada en sectores económicos estratégicos, entre otras acciones, que encaminen a Cuba hacia la economía de mercado. Además, defiende la necesidad de que la reforma económica sea complementada con cambios en los campos político, ideológico y jurídi$\mathrm{co}$, que generen, no solo mayor certidumbre acerca de los resultados de la ola reformista, sino que también aseguren sus efectos en la calidad de vida de los cubanos.

Ahora bien, si Cuba pretende seguir la senda exitosa trazada por Estados socialistas como China y Vietnam, debe enfrentarse con diferencias que pueden dilatar, si no impedir, dicho propósito. Como lo subrayan Sweig y Bustamante, "Cuba es un país subdesarrollado con los problemas del mundo desarrollado" (2013: 97), por cuanto tiene un alto porcentaje de población mayor a 60 años $(18 \%)$ y su economía actual está fuertemente

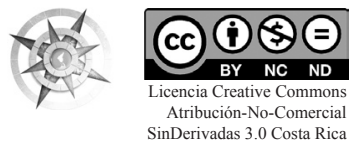

Nuevos vientos soplan en el malecón de La Habana: Reformas económicas y cambio político en Cuba Jhany Marcelo Macedo Rizo 
inclinada hacia el sector de servicios, que constituye cerca del $75 \%$ del PIB de la isla, en contraposición a un bajísimo nivel industrial y limitadas tasas de ahorro e inversión. Por ello, "las exportaciones de servicios (principalmente profesionales de la salud), combinadas con el turismo y las remesas, constituyen la principal defensa del país contra un déficit sostenido en la balanza de pagos" (ibíd.).

Lo anterior hace más imperioso el fortalecimiento del sector exportador (con la diversificación productiva y de destinos a la que ya se ha hecho referencia), el fomento de un mercado interno más amplio y dinámico y, sobre todo, el incremento decidido de la inversión. En aras de estos objetivos se ha propuesto, además del aumento de las microempresas y del sector cooperativo, una mayor tasa de empleo privado, la utilización (en usufructo) de las tierras cultivables del país -que para el 2005 era del 20\% del área total y ha aumentado progresivamente año a año-, y la renovación del puerto de Mariel, en La Habana, para facilitar el comercio internacional a escala. Además, el fomento de la inversión extranjera, que es el quid de una ley aprobada en abril del 2014, modificatoria de la original de 1995, la cual crea mayores incentivos para el capital foráneo. Como Sweig y Bustamante lo defienden, "Cuba necesita, con urgencia, inversionistas medianos y grandes. En última instancia, sólo las inversiones cuantiosas pueden ayudar a solucionar el principal problema económico de Cuba: su empobrecida base productiva" (2013: 101). Este parece ser un razonamiento compartido, en el sentido que el aumento de la inversión es fundamental para superar en definitiva la permanente crisis de la isla, para lo cual será necesario desarrollar un modelo más pragmático y menos atravesado por el plano ideológico-político. "Para el régimen castrista se trata de actualizar el modelo, porque a pesar de las recientes reformas, la economía sigue estancada, pero más allá de los eufemismos, lo que demuestra la ley es que la única manera de mantener a flote el régimen socialista es, paradójicamente, abrirse al capitalismo. $\mathrm{Y}$ no es un misterio combinar la ideología con el pragmatismo. Ya China lo hizo y ahora Raúl Castro parece dirigirse en ese mismo camino..." (semana. com, 2014).

\section{Conclusión}

Tras la breve revisión que se ha llevado a cabo, se puede afirmar que la situación actual de Cuba, así como sus perspectivas para los próximos

62 Nuevos vientos soplan en el malecón de La Habana: Reformas económicas y cambio político en Cuba Jhany Marcelo Macedo Rizo 
años, conducen a una gran paradoja, ya que, por una parte, el crecimiento económico solo se podrá dar a través de una liberalización de la economía, la cual necesariamente tendrá que venir acompañada de una ampliación de libertades civiles y políticas y una democratización generalizada de la vida social. Sin embargo, por otra parte, el mejoramiento de las condiciones de vida y el aseguramiento de un crecimiento sostenido (alcanzable vía liberalización) pueden servir a la vez como elemento de refuerzo del modelo político vigente.

Lo importante a tener en cuenta, bien sea que las reformas económicas tengan o no incidencia en el régimen político, es que estas deben ser, en todo caso, graduales, pues de lo contrario pueden generar terribles efectos sobre la sociedad. Una apertura acelerada o apresurada, una reducción abrupta en la provisión de bienes y servicios por parte del Estado y la entrega de estos al mercado, pueden provocar el enriquecimiento de algunos con un empobrecimiento correlativo de la mayoría de la población, teniendo en cuenta la disparidad monetaria actual y la capacidad adquisitiva vigente de los cubanos, conllevando así a un dramático fenómeno de reestratificación social, que minaría las bases de igualdad sobre las que se ha fundamentado el modelo socialista.

Al respecto, Sweig y Bustamante también se inclinan por que las reformas sean graduales, aunque su enfoque está más orientado hacia el impacto que una apertura inmediata causaría sobre el régimen político, lo que a su juicio merece la mesura y progresividad del gobierno cubano. En este sentido, afirman que "Castro parece reconocer que atraer inversión extranjera, descentralizar el gobierno y ampliar aún más el sector privado son las únicas maneras de abordar esta situación en el largo plazo. Sin embargo, es poco probable que el gobierno proceda precipitadamente. Las autoridades están renuentes a agitar las aguas del entorno político nacional, y los ciudadanos y los líderes del partido, por igual, retroceden ante la perspectiva de una terapia más radical. El aumento de las protestas públicas en China y en Vietnam contra la desigualdad y la corrupción rampante sólo han reforzado la preferencia del gobierno cubano por el gradualismo" (2013: 101).

Así las cosas, con el fin de evitar un colapso del modelo social construido desde el Estado durante más de cincuenta años, además del carácter paulatino en la implementación de

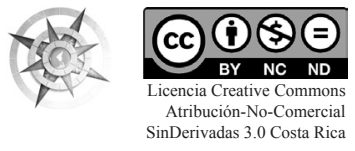

Nuevos vientos soplan en el malecón de La Habana: Reformas económicas y cambio político en Cuba Jhany Marcelo Macedo Rizo 
las medidas de apertura económi$\mathrm{ca}$, se requiere el mantenimiento de políticas sociales y distributivas que han resultado beneficiosas durante el socialismo, además de otras disposiciones, que van más allá de la provisión de bienestar por parte del gobierno y se encuadran, por ejemplo, en el sostenimiento de la seguridad interna, a través del control de armas que tan rígidamente se ha ejercido durante las últimas cinco décadas y ha generado una bajísima tasa de violencia interna.

La combinación de estas medidas quizá conduzca a un modelo particular que siga siendo característico de Cuba, que ha sabido sostener un socialismo tropical "a la cubana" durante mucho tiempo, pero que ahora, ante la necesidad de superar su crisis estructural, se abre a nuevas posibilidades que se erigen como una amalgama de opciones paradójicas.

\section{Referencias}

Alonso, José Antonio y Pavel Vidal. (2013) ¿Quo vadis, Cuba? La incierta senda de las reformas. Madrid, Libros de La Catarata.

Castañeda, Rolando H. (2009) "La ayuda económica de Venezuela a Cuba: situación y perspectivas - ¿Es sostenible?", en Cuba in transition. Vol. 19, pp. 389-400. Maryland, ASCE.
CEPAL. (2000) Estudio económico de América Latina y el Caribe, Capítulo Cuba. Santiago de Chile, CEPAL.

García Molina, Jesús M. (2005) La reforma monetaria en Cuba. México D.F., Naciones Unidas.

García Rabelo, Margarita y Vilma Hidalgo de los Santos. (2013) Modelo económico y social cubano: nociones generales. La Habana, Editorial UH.

Haney, Patrick Jude y Walt Vanderbush. (2005) The Cuban embargo: the domestic politics of an American foreign policy. Pittsburgh, University of Pittsburgh Press.

Mesa-Lago, Carmelo. (2009) "Balance económico-social de 50 años de revolución en Cuba", en América Latina Hoy. No. 52, pp. 41-61. Salamanca, Universidad de Salamanca.

Mesa-Lago, Carmelo. (2012) Cuba en la era de Raúl Castro: reformas económicas y sus efectos. Madrid, Colibrí.

Palacios Cívico, Juan Carlos. (2012) "La reforma de la economía cubana. Evaluación de su potencial impacto en el crecimiento económico", en Papeles de Europa. No. 24, pp. 16-53. Madrid, Universidad Complutense.

Pardo Martínez, Orlando y Eurípides Valdés Lobán. (1999) "Fundamentos del bloqueo a Cuba: análisis crítico", en Reflexión Política. Vol. 1, No. 2, diciembre, pp. 21-27. Bucaramanga, Universidad Autónoma de Bucaramanga.

Pérez Villanueva, Omar y Ricardo Torres Pérez. (2013) Cuba: la ruta necesaria del cambio económico. La Habana, Instituto Cubano del Libro.

64 Nuevos vientos soplan en el malecón de La Habana: Reformas económicas y cambio político en Cuba Jhany Marcelo Macedo Rizo

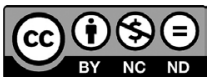


Rodríguez, José Luis. (2016) “Los Lineamientos para la Política Económica y Social y su evolución 2011-2016" en Cubadebate. Disponible en: http://www. cubadebate.cu/opinion/2016/04/14/ los-lineamientos-para-la-politica-economica-y-social-y-su-evolucion-2011-2016/\#.V-xD2IVOLIU [Consultado el 10 de mayo de 2015].

Sin nombre de autor. (2014) "El cuban dream ¿se hará realidad?", en Revista Semana. Disponible en: www.semana. $\mathrm{com} / \mathrm{mundo} /$ articulo/la-nueva-leyde-inversion-extranjera-en-cubabusca-abrir-la-economia/382654-3 [Consultado el 5 de abril del 2014].
Sweig, Julia y Michale J. Bustamante. (2013) "Cuba después del comunismo: Las reformas económicas que están transformando la isla", en Foreign Affairs Latinoamérica. Vol. 13, No. 4, octubre-diciembre, pp. 94-106.

Virgili, Teresa y Cristina Xalma. (2007) "Cuba: reforma económica y modelo social”, en Análisis Económico. Vol. XXII, No. 50, pp. 79-101. México, Universidad Autónoma Metropolitana Azcapotzalco.

White, Nigel D. (2015) The Cuban Embargo under International Law: El Bloqueo. New York, Routledge Research in International Law. 